\title{
Un acercamiento a la comprensión de la agresión y la violencia humana
}

Humberto Yáñez-Canal*

Doctor en Paz y Conflictos. Profesor investigador, Facultad de Psicología, Universidad Cooperativa de Colombia, Santa Marta, Colombia.

Correo electrónico:

humberto.yanezc@campusucc.edu.co

Recibido: 10 de octubre del 2014

Aprobado: 11 de noviembre del 2015

Cómo citar este artículo: Yañez-Canal, H. (2015). Un acercamiento a la comprensión de la agresión y la violencia humana. Pensando Psicología, 11(18), 169-183. doi: http:// dx.doi.org/10.16925/pe.v11i18.1227

\section{Resumen}

Propósito: reflexionar sobre algunas posibles confusiones dadas en la práctica social y comunicativa de los profesionales en educación y el tratamiento social al abordaje de la violencia escolar. Al revisar el asunto, se detecta cómo algunas de las confusiones básicas parecieran darse alrededor del uso de los conceptos de agresión y violencia, los cuales algunos autores tratan de manera indiferenciada como sinónimos, desconociendo los esfuerzos de las ciencias sociales por entenderlos y explicarlos. Abordar esta confusión y presentar opciones con el fin de entender las implicaciones de estos dos términos es el propósito de este texto. Tema: el abordaje de la violencia escolar ha estado al orden del día durante los últimos años. De manera recurrente, publicitan casos extremos acudiendo a expertos que dan explicaciones y soluciones, aunque parece que el asunto de las prácticas violentas se mantiene y los esfuerzos fueran insuficientes. Desarrollo: se abordan las confusiones en las definiciones de los diccionarios, se examinan sus significados etimológicos y se revisa el uso y sentido de la agresión y la violencia desde la sociología, la política y la psicología. Conclusiones: se propone una mirada de los dos conceptos en la que se establecen sus diferencias, pero la cual parte de un mismo fenómeno expresado en intensidades y frecuencias graduales. De igual forma, se busca reconocer que todo movimiento dado en espacios limitados es susceptible de ser percibido como agresivo por quien es sujeto de esa fuerza.

Palabras clave: agresión, alteración, confusión, contacto, espacios cerrados, organización social, violencia. 


\title{
An Approach to Understanding Aggression and Human Violence
}

\begin{abstract}
Purpose: To reflect on certain possible confusions that arise in the social and communicative practice of professionals in the field of education and social treatment when dealing with school violence. A review of the matter showed that some of the basic confusions seem to arise around the use of the concepts of aggression and violence, which some authors treat as though they were synonyms, ignoring efforts by the social sciences to understand and explain them. The purpose of this text is to deal with this confusion and present options for understanding the implications of these two terms. Topic: Dealing with school violence has been on the agenda over the past two years. Repeatedly, extreme cases are published asking experts to provide explanations and solutions, although it seems that violent practices persist and efforts have been insufficient. Development: Confusions in the definitions that appear in dictionaries are examined, etymological significances are addressed and the use and meaning of aggression and violence from the perspective of sociology, politics and psychology are reviewed. Conclusions: A review of the two concepts is proposed in which their differences are established, but which is based on the same phenomenon expressed in gradual intensities and frequencies. The text also seeks to recognize that all movements in limited spaces are susceptible to being perceived as aggressive by whoever is subjected to that force.
\end{abstract}

Keywords: aggression, alteration, confusion, contact, closed spaces, social organization, violence.

\section{Uma aproximação à compreensão da agressão e da violência humana}

\section{Resumo}

Propósito: refletir sobre algumas possíveis confusões dadas na prática social e comunicativa dos profissionais em educação e no tratamento social à abordagem da violência escolar. Ao revisar o assunto, identifica-se como algumas das confusões básicas parecem acontecer sobre o uso dos conceitos de agressão e violência, os quais são tratados por alguns autores de forma indiferenciada como sinônimos, desconhecendo os esforços das ciências sociais por entendê-los e explicá-los. Abordar essa confusão e apresentar opções a fim de entender as implicações desses dois termos é o propósito deste texto. Tema: a abordagem da violência escolar tem sido o tema do dia durante os últimos anos. De maneira regular, publicam casos extremos recorrendo a especialistas que dão explicações e soluções, embora pareça que o assunto das práticas violentas se mantém, e os esforços foram insuficientes. Desenvolvimento: abordam-se as confusões nas definições dos dicionários, examinam-se seus significados etimológicos e revisam-se o uso e o sentido da agressão e da violência a partir da sociologia, da política e da psicologia. Conclusões: propõe-se uma interpretação dos conceitos na qual se estabeleçam suas diferenças, mas que parta de um mesmo fenômeno expresso em intensidades e frequências graduais. Do mesmo modo, busca-se reconhecer que todo movimento dado em espaços limitados é suscetível de ser percebido como agressivo por quem é sujeito dessa força.

Palavras-chave: agressão, alteração, confusão, contato, espaços fechados, organização social, violência. 


\section{Introducción ${ }^{1}$}

El presente texto se origina a raíz de la curiosidad que sucita responder a la pregunta sobre qué es lo que pasa - lo que falla - en los acercamientos e intervenciones sobre el fenómeno de "la violencia escolar", el cual ha venido recibiendo tratamiento repetitivo como si se tratara de cualquier ejercicio de venta que compete al mercadeo del mundo de la moda.

Reconociendo la buena fe y licitud de muchos que realizan acciones sobre el fenómeno enunciado, y respetando a quienes actúan con coherencia en sus definiciones y creencias, tanto filosóficas como metodológicas, es necesario reconocer también que por más de 20 años se ha merodeado esta temática en el universo académico de occidente. En estas indagaciones que se han llevado a cabo, las explicaciones se reiteran, las lecturas se repiten y las urgencias administrativas se mantienen, lo cual promueve una viciosa circularidad de opiniones que surgen de boca de diferentes "expertos", aparecidos episódicamente independientemente de que, en términos de lo real, los daños, afrentas, ofensas y agravios continúan al interior de las instituciones formalmente señaladas y asignadas para formar, desarrollar y educar.

Con la convicción en la necesidad de reflexionar sin los afanes de quienes urgen medidas, soluciones o justificaciones para vigilar y castigar, el autor se ha planteado la opción de realizar una revisión conceptual sobre la agresión y la violencia, en procura de identificar formas que posibiliten la comprensión de la naturaleza y la dinámica relacional de esta singular forma de contacto interhumano. De entrada, y al reconocer el escenario de las posibles explicaciones e intervenciones que se dan sobre el fenómeno denominado "la violencia escolar", se reiteran diversas maneras de abordarla y de caracterizarla. Por un lado, la polisemia de palabras o términos usados

\footnotetext{
1 El presente artículo se apoya en los resultados de una investigación documental realizada de manera continua desde el 2009 hasta la fecha, y la cual tiene como referente de fuentes primarias textos de los autores citados y algunas notas extraídas de la investigación doctoral del autor. Como fuentes secundarias se refirieron artículos de prensa sobre el fenómeno en cuestión y diversos textos publicados sobre el tema que pueden ser reconocidos como literatura gris. De manera que se utilizó la metodología pertinente a las investigaciones documentales. Para la realización del artículo se optó por seleccionar definiciones y temas de algunos autores estudiados, con el propósito de permitir la referencia de conjunto por parte del lector. La construcción del texto emana de la concepción humanista del autor.
}

alternativamente de forma indiscriminada a de fin definir el fenómeno o los fenómenos que se presentan en la complejidad de lo cotidiano de las instituciones educativas. Por ejemplo, se fuerzan las palabras a entrar en cualquiera de los cajones que las definen, independientemente de su heterogeneidad, causalidad, pertinencia o casualidad. Es así como se habla indiscriminadamente y con fuerza de sinónimos de bullying, matoneo, acoso, intimidación, agresividad, agresión y violencia, acompañados de adjetivos tales como agresivo, violento, ofensivo, conflictivo, psicópata, criminal, enfermo, etc., los cuales se asocian con diferentes explicaciones de naturaleza monocausal y con giros discursivos en los que el espectro del control y el aroma de castigo se asientan indisolublemente.

$\mathrm{Al}$ realizar un inventario de estos ejercicios anclados en la causalidad, se encuentran desde los que se caracterizan por convocar la atención sobre la búsqueda de "culpables" (los cuales estimulan discursos legales y normativos a fin de obligar a la acción desde el amparo del monopolio de la autoridad y su discrecionalidad para vigilar y castigar), hasta los que, pasando por las usuales moralizaciones genéricas, sustentan que todo es producto de la falta de valores morales (refrendan su implícito modelo ideal, en el cual conciben y demandan a la especie humana la condición de ser y llegar a ser un ejército de ángeles que actúan como cultores de la disciplina y el orden en tanto condición de su existencia).

Indisolublemente ligados a estos ejercicios, se llega a los que configuran alegremente patologías posmodernas abarcantes de sinnúmero de conductas, en las cuales la desobediencia, la actividad excesiva o fuera del control y del orden esperado, o la pasividad ante los ejercicios reglados por la autoridad, señalan dificultades de adaptación y de salud que terminan invocando la intervención de especialistas tales como médicos, psiquiatras, psicólogos, educadores y expertos en reeducación ${ }^{2}$. Estos, en su automático y soterrado papel de sustentadores ideológicos de la norma y los ejercicios de poder de la administración

\footnotetext{
2 Es pertinente llamar la atención sobre estas propuestas conocidas como "re-educativas", pues parecieran de naturaleza aérea en el sentido de pretender "re-educar" a quienes nunca habían sido educados, pues sus prácticas sociales, al parecer, desde sus inicios relacionales no se adherían a los rituales formales, criterios explicativos, valoraciones morales y conductas éticas que se consideran "normales o esperadas" desde la óptica de los modelos de hombre/ mujer y de comportamiento, los cuales se referencian como principio del orden y la regulación social y que configuran el modelo del "hombre originalmente educado", o que se "desvió".
} 
institucional, se perfilan desde un claro rol de agentes de y para el control social del ejercicio cotidiano, al convivir durante muchas horas diarias al interior de los muros concretos y simbólicos en los cuales se ordena la praxis de las relaciones interhumanas.

$\mathrm{Y}$ en esa multiforme gama en la que se expresan las tendencias y recursividades humanas se pueden encontrar diversos mundos paralelos, los cuales se esfuerzan por escapar a las justificaciones institucionales y a la estela de actos y discursos formales de quienes, en su afán de intervención y explicación definitiva, van arrastrando y repartiendo culpas a padres, docentes, directivos e, incluso, sobre estructuras cerebrales. Recursividades que permiten escapar o empiezan a escabullirse también, merced el uso de los mismos recursos miles de veces usados, de las pretensiones políticas que traduce el asunto en soluciones de ley como en el caso de Colombia ${ }^{3}$. Y, es así como en la búsqueda de soluciones se va posibilitando la apertura de brechas o senderos en los que la gente incrédula transita hacia la búsqueda de otro tipo de recursos y prácticas ofertadas por lo que se conoce como saberes tradicionales, cosmologías o entendimientos de nueva era o de última generación, a fin de entender o resolver las usuales contradicciones y manifestaciones al interior de su praxis social. $\mathrm{Y}$ es en este escape de los límites institucionales en el cual también surgen otras maneras de pensar que, evadiendo el individualismo, el pragmatismo y las urgencias del pensamiento oficial, examinan alternativas comprensivas conducentes a colectivizar el fenómeno y proponer su adscripción a lenguajes implicativos, colectivizantes y de lectura estética.

\footnotetext{
3 El autor cree que el pretendido protagonismo de lo legal aporta limitaciones adicionales para la comprensión del asunto, al introducir criterios de obligatoriedad en las conductas, pautas de comportamiento formal y la recurrencia histórica en la que uno de los actores (directivos/docentes) sean a la vez jueces y parte, como es el caso que recientemente empieza a configurarse en Colombia con la expedición de la Ley 1620 del 15 de marzo del 2013, denominada de la "Convivencia Escolar", y cuyo contenido señala pautas normativas para el ejercicio de la actividad docente y organizacional, y crea formalmente el Sistema Nacional de Convivencia Escolar y Formación para el Ejercicio de los Derechos Humanos, la Educación para la Sexualidad y la Prevención y Mitigación de la Violencia Escolar. Además, no es secreto la potencial ineficacia de lo legal como instrumento en la gestión de diseños preventivos, ya que su estructuración semántica discurre a partir de la definición y diferenciación del hecho cumplido y nunca de la comprensión holística de la dinámica interhumana, la cual no escapa a la alta probabilidad de agresiones, conflictos, tensiones y enfrentamientos circunstanciales que se detienen en el tiempo y optan por formas violentas evidentes o soterradas.
}

\section{Revisando prácticas sociales, definiciones y conceptos}

\author{
Dos significados diferentes y tres \\ confusiones
}

De las consideraciones anteriores surge esta investigación documental cuyos resultados a continuación se exponen, y la cual parte de afirmar que las palabras agresión y violencia no tienen el mismo significado, y cómo la confusión en su uso se presenta y se sostiene, al menos, desde tres fuentes diferentes presentadas en la figura 1.

Como primera fuente que promueve la confusión se encuentra el continuo uso indiferenciado de estos conceptos por parte de los medios de comunicación, en su costumbre de "coloquiar"4 los términos que proponen las teorizaciones de la ciencia y el uso adjetivado que sus discursos y narrativas, anclados en lo publicitario, le imponen en sus ejercicios de validación de la estructura del consumo y la rentabilidad social.

Como segunda fuente se suma la falta de profundización semántica y teórica de algunos profesionales y educadores ${ }^{5}$. Estos acogen descontextualizados los usos lingüísticos y, en su afán pragmático de conseguir resultados de intervención o actualizarse con las "últimas tecnologías", van generado la costumbre de usar los conceptos de agresión y violencia como si fuesen sinónimos y pudiesen, entonces, utilizarse indiferenciadamente para señalar y calificar las acciones por medio de las que alguien o algo contrasta, molesta, fastidia, afecta, reprocha, censura, descalifica, irrita, ofende, agravia o daña a otro. El autor cree que la confusión creada por esta práctica espontánea y elemental de descontextualizar y cercenar la

4 Se emplea el término "coloquiar" con el fin de indicar la tendencia de los medios de comunicación de usar conceptos elaborados por la ciencia y darles tratamiento de sinonimia con las palabras usadas en el lenguaje coloquial, lo cual conlleva a que la precisión y fineza de los significados conceptuales quede reducida a la interpretación simple de las explicaciones elementales de la praxis social cotidiana.

$5 \quad$ Esta aseveración se presenta a partir de experiencias directas en las cuales se ha percibido que algunos educadores y promotores de ideas o procedimientos, en su afán por hacerse entender por sus interlocutores, acuden al uso de términos de manera genérica pretendiendo que el auditorio entienda la propuesta que el oferente desea impulsar como válida y conveniente. Cabe aclarar que este es un tema que se está delineando para un posible proyecto investigativo. 
historicidad de los conceptos, contribuye a dificultar los acercamientos a la comprensión de los fenómenos emergentes en los contactos entre las personas y, además, conlleva implícito el riesgo de sesgar las lecturas e interpretaciones de lo agresivo y lo violento facilitando posturas adjetivadas de quienes a nombre de la técnica, la moral o la autoridad, emiten juicios de valor y afirmaciones para condenar y convocar vigilancias, controles y castigos.

\section{Dos significados diferentes:}

3 Confusiones:

Partimos de afirmar que las palabras agresión y violencia no tienen el mismo significado y que la confusión cotidiana en su uso se presenta y se sostiene desde tres (3) fuentes diferentes:

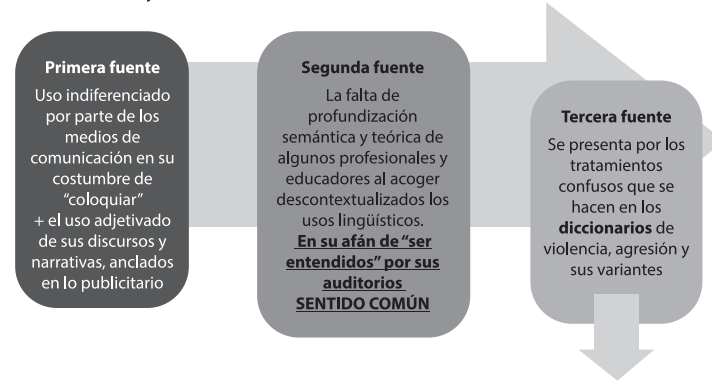

Figura 1. Fuentes de las confusiones. Elaboración propia.

Como tercera fuente de confusión se presentan los tratamientos de los términos que se encuentran en los diccionarios, lo cual a partir de la revisión realizada en esta investigación permite mostrar dos puntos.

1. Respecto al término violencia, esquematizado en la figura 2, sufre un trato confuso en los diccionarios pues se define en círculo vicioso con el adjetivo violento y el verbo violentar; es decir, no se le da una identidad (como corresponde a todo sustantivo). Así, en los diccionarios de la Real Academia Española -RAE- (1992, p. 1345) y el de María Moliner (1983, p. 1534), se define haciéndolo depender del adjetivo violento, el cual ejerce como definidor, negándole al sustantivo violencia una identidad, existencia real, independiente o individual, tal como corresponde lingüísticamente al tratamiento de todo sustantivo, es decir, se hace depender del adjetivo violento (RAE, 1992, p. 1345; Moliner, 1983 p. 1534). O bien se correlaciona con el verbo violentar (RAE, 1992, 1345, Moliner, 1983, p. 1534), referido a otro o a sí mismo (violentarse), de una manera circular en la que el uno define al otro y viceversa. Ahora bien, como parte de la confusión que emerge de la mencionada circularidad de su uso en función del verbo y del adjetivo, ignoran las posibles atribuciones singulares que le corresponden como sustantivo y lo caracterizan como un efecto, resultado de lo que se hace con fuerza extrema, con brusquedad, con "ímpetu" extraordinario, es decir, que se trata de un movimiento (acción) ejecutado de manera impositiva o forzosa, como evidencia de superioridad de fuerza hacia el otro, es decir, sobre otro. De esta manera se reafirma lo extraño de su tratamiento pues, en otro giro, su definición se da en función del hecho que causa, de su efecto, y se percibe su actuación como una forma usual de aplicación de poder de manera impositiva o forzosa, sin el consentimiento o negando los derechos del otro.

Tratamientos confusos que se hacen en los diccionarios 1. Respecto al término de violencia

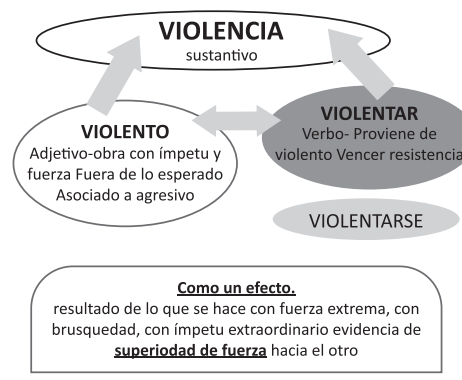

VIOLENCIA

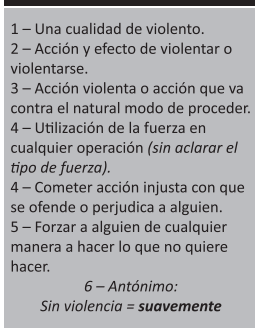

Figura 2. Tratamientos confusos de la violencia en los diccionarios. Elaboración propia.

2. Respecto del término agresión (RAE, 1992, p. 243, Moliner, 1983, p. 89; véase la figura 3), las acepciones que plantean los diccionarios y sus variantes tampoco parecen fiables. Al revisar sus definiciones se evidencia ambigüedad, contradicción y falta de precisión, además de la circularidad con que apoyan de manera interdependiente el sustantivo agresión del verbo agredir (RAE, 1992, p. 43, Moliner, 1983), y, así mismo, sobre el adjetivo agresivo (RAE, 1992, p. 43, Moliner, 1983, p. 89). Lo anterior se evidencia, además, cuando al profundizar se observa que la RAE apoya su definición semántica en el verbo acometer, con lo cual contradice su definición en términos de efecto que se relaciona con muerte, herida o daño, pues este verbo acometer se define en el mismo diccionario como "embestir con ímpetu y ardimiento", sustrayéndole su carga de intencionalidad adjudicada con la preposición para. Además complementa el acometer como "venir, entrar, dar repentinamente", con "emprender, intentar", "decidirse a una acción o empezar a ejecutarla", "solicitar, pretender algo de alguien, proponérselo, inducirle a ello", y "cometer yerros o malas acciones". Moliner (1983), por su 
parte, define acometer como: "Atacar físicamente a alguien, o atacar un sitio donde hay alguien como dirigirse violentamente o con furia contra una cosa inanimada. Intentar conquistar la voluntad de alguien para algo. Atacar. Comenzar una empresa o trabajo. Emprender. Proponer".

Como verbo, agredir no recibe ningún tratamiento y lo meten en un círculo vicioso con el sustantivo agresión, es decir, el uno se define por el otro y viceversa, de manera que como adjetivo resalta su consideración en cuanto calificativo que se aplica a alguien en los parámetros de una forma de rechazo a su conducta, implicando un sesgo moral que lleva a pensar que esta fuente no es confiable para el manejo conceptual de los términos en la investigación y la teoría científica.

Y a fin de redondear la imprecisión que caracteriza a los diccionarios, basta revisar lo que señalan sobre la palabra agresividad - que tanto se usa indiferenciadamente como sinónima de agresión por algunos oferentes de los asuntos que competen a esta ponencia-, aclarando que no se encontró un término homólogo en las acepciones posibles de violencia (¿acaso podría ser violentalidad?).

El diccionario de la RAE (1992, p. 43) lo sitúa procedente del adjetivo agresivo, tratándolo como la "tendencia a actuar o a responder violentamente", y relacionándolo con el sustantivo acometividad, el cual define como la "propensión a acometer, atacar, embestir", y con "brío, pujanza, decisión para emprender algo y arrostrar sus dificultades”. Introduce una paráfrasis en la que subraya la importancia y estímulo de su cualidad en el uso por las personas al decir "su acometividad en el mundo de los negocios le proporciona grandes éxitos”. El diccionario de María

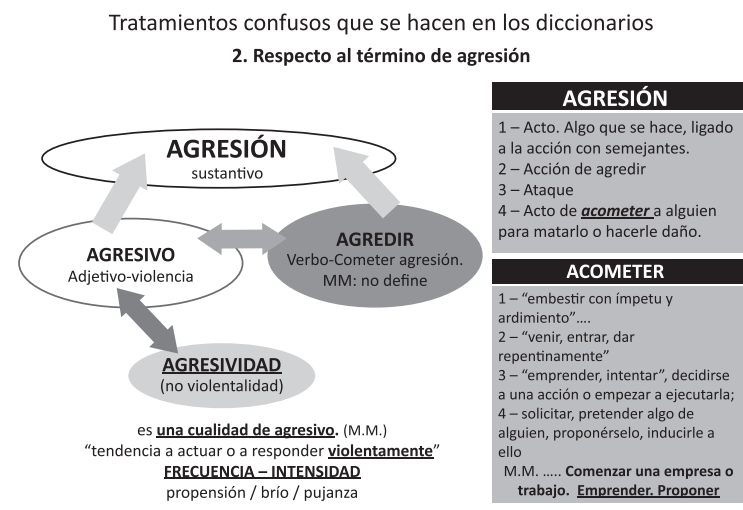

Figura 3. Tratamientos confusos de agresión en los diccionarios. Elaboración propia.
Moliner (1983, p. 89), de agresividad dice simplemente que es una cualidad de agresivo.

\section{Buscando claridad: una revisión de conceptos y de autores}

Las tres confusiones revisadas llevan a buscar claridad y demandan incursionar en cómo entender en un lenguaje de investigación el asunto. Por tanto, se decide abordar la cuestión desde la etimología como otra forma de comprender significados de la agresión y la violencia, así como recrear - de manera rápidaa los investigadores del asunto desde la ciencia social, de manera que se mire lo que desde la sociología propone Galtung, y desde los estudios del comportamiento humano lo que proponen Freud, Lorenz, Dollard y Miller, y Bandura.

\section{Otra forma de mirar para comprender significados: lo etimológico}

Recreando el contraste que emerge de lo etimológico e incursionando en los significados que de ellos emergen, se encuentran los siguientes que nos introducen al sendero comprensivo de lo original, la historicidad y hasta las posibles mutaciones de los conceptos de violencia y agresión.

\section{Sobre la etimología de violencia}

Ilustrativa nos parece la forma como el etimólogo español Mario Arnal (2009b) - cuyo tratamiento se presenta resumido en la figura 4 -, en su página web analiza violencia:

Del latín vis, que significa fuerza, se forma el adjetivo violens, violentis (violento), obtenido del adjetivo latino más usual violentus - a -um. Homo violentus (hombre violento), imperium violentum (orden violento, poder despótico), ingenium violentum (carácter violento), verba violenta (palabras violentas) eran expresiones muy usuales en latín.

El mismo licenciado en una digresión sobre la palabra vigor plantea una relación entre esta y la violencia en el caso de la aplicación de la ley:

Es que las cosas son tan primitivas como las palabras antiguas: vigor es un cultismo que se mantiene tal como salió del latín: vigor vigoris es su enunciado, y su origen el verbo vígeo, vigere, vígui. Un compuesto 
de vis, que significa fuerza, violencia, más el verbo ago, ágere, egi, actum, que significa conducir, guiar. Es decir que no se trata de violencia sin más, movida por la ira o por la ambición, sino de una violencia conducida, organizada, previsible, racional. Lo que les corresponde a las leyes. Pero es que el vigor no se predica sólo. Más aún: los romanos tenían tan sumamente claro que la violencia es consustancial a las leyes (su fuerza es como la energía: está ahí, en ellas, y sólo se pone en ejercicio cuando es necesario); tan claro lo tenían los romanos, que ni siquiera se les ocurrió explicitarlo: de manera que nunca asociaron este grupo léxico a las leyes. Fue precisamente cuando estas se postularon como alternativa a la violencia, cuando fue preciso advertir (retóricamente, claro está), que estas eran capaces y estaban legitimadas per se para usar la violencia.

Y en esta lógica del razonamiento etimológico se encuentran los comentarios de la página web elcastellano.com (s. f.), en la cual se da la afirmación según la cual la violencia fue asociada desde tiempos muy remotos a la idea de la fuerza física.

Los romanos llamaban vis, vires a esa fuerza, al vigor que permite que la voluntad de uno se imponga sobre la de otro. Vis tempestatis se llama en latín el 'vigor de una tempestad'. En el Código de Justiniano se habla de una 'fuerza mayor, que no se puede resistir' (vis magna cui resisti non potest). Vis dio lugar al adjetivo violentus, que aplicado a cosas, se puede traducir como 'violento, 'impetuoso, 'furioso, 'incontenible, y cuando se refiere a personas, como 'fuerte', 'violento,' 'irascible'. De violentus se derivaron violare --con el sentido de 'agredir con violencia,' 'maltratar', 'arruinar', 'dañar'-- y violentia, que significó 'impetuosidad, 'ardor' (del sol), 'rigor' (del invierno), así como 'ferocidad', 'rudeza' y 'saña. Cabe agregar que vis, el vocablo latino que dio lugar a esta familia de palabras, proviene de la raíz prehistórica indoeuropea wei- 'fuerza vital' (Elcastellano.com, s. f.)

\section{Sobre la etimología de agresión}

Respecto a la agresión el referido licenciado Mario Arnal (2009a; véase figura 5), hace precisiones interesantes al plantear que la forma negativa en que se lee la palabra agresión en la lengua española no tiene asidero en el uso dado por los romanos, quienes la usaron muy poco con esta significación. Afirma que su verbo original aggredior, aggressus sum,

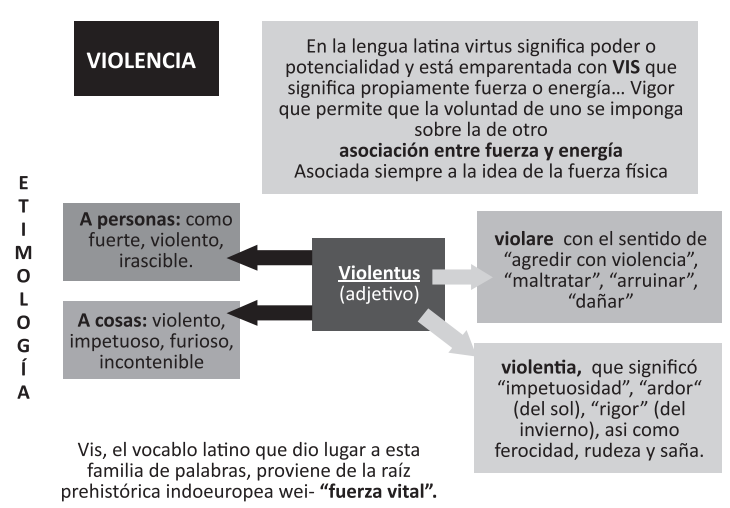

Figura 4. Tratamientos etimológicos de la violencia. Elaboración propia.

aggredi (de ad más gradior, gressus sum, gradi), significa simplemente "ir hacia", "dirigirse a", "acercarse", "aproximarse".

Plantea este lingüista que gradior significa tan solo "ir", "caminar", "avanzar"; y gradus es solamente un paso. Así que desde la perspectiva de su origen etimológico, agredir es algo tan neutro como acercarse: "Por su origen y por los elementos que la forman, la palabra agresión no tiene nada de agresiva" (Arnal, 2009b). De igual forma, sostiene una interpretación interesante en la que señala como lo que le incorpora la adjetivación de peligroso u ofensivo a la palabra agresión es la percepción del acto por parte de quien ha demarcado límites, caminos, territorios para sí, y siente que el otro se los ha invadido, vulnerado. Surge entonces esa connotación de daño de lo agresivo, como resultado de la costumbre de marcar territorios e introducir en el lenguaje la idea de territorialidad con obligatoriedad de protegerla o defenderla, pretendiendo que los demás asuman ese coto como inaccesible e intocable para ellos, y en el cual cualquier acercamiento a lo que ha incorporado como suyo determina el uso dado comúnmente para el término. Propone este autor el ejemplo del vendedor que, en el propósito de que entre al terreno económico de otro se le pide agresividad, a fin de exponer cómo en nuestro subconsciente léxico persiste la idea de que una agresión es al fin y al cabo un acercamiento.

Por otra parte, en el sitio web Página del idioma español (2009) se señala la gestión o proceso de formación del significado que se dio en la formación de algunas palabras, entre ellas agresión. Dada la estructura especializada del lenguaje, es necesario transcribirla textualmente: 
Para referirse al acto de caminar, los latinos usaban la raíz grad-, que se encuentra en gradi 'caminar', 'dar pasos'. Gressus, el participio pasivo de este verbo, dio lugar, mediante el agregado de prefijos, a numerosas palabras en las lenguas romances. Así, de la idea de dar pasos hacia adelante, surgió la palabra progreso; de la de dar pasos hacia atrás, nació regreso; de la de ir en sentido opuesto a otra persona no se formó 'agreso', como hubiéramos esperado, sino agresión; de la de alejarse de algo o de alguien, se formó digresión; de la de entrar en un lugar, se generó ingreso, y de la de caminar juntos hacia un punto de reunión, devino la palabra congreso.

Por su parte, el investigador Jacques van Rillaer (1978) refiere:

La palabra «agresión» aparece en las lenguas románicas a partir del siglo XIV, mientras que el término «agresividad» es de uso bastante reciente. Por ejemplo, en castellano se registra el uso del término agresión a partir de 1502, y el de agresividad sólo desde 1910. Este último se incorpora al Diccionario Real Academia sólo a partir de la decimosexta edición (1939). (p. 117).

A los anteriores tratamientos de agresión sumamos, en aras de reafirmar el significado original del concepto, lo que afirma Erich Fromm (1982, p. 195),

1-Ad + gradior: significa paso, marcha, aproximación, avance, subida, escalón. Ad (dirigirse hacia, o contra ir hacia, dirigirse a, acercarse, aproximarse.) + gresus (marchar, dirigirse, avanzar) del mismo modo que regredi significa "retroceder". Etimológicamente ligada a invadir un territorio, afectarlo en la medida en que se marcha contra él.

- Agredir es algo tan neutro como acercarse. En nuestro subconsciente léxico persiste la idea de que una agresión es al fin y al cabo un acercamiento.

o de peligroso u ofensivo es la percepción del acto por parte de quien ha demarcado límites, caminos, territorios para sí y siente que el otro se los ha invadido, vulnerado y tiene obligatoriedad de protegerlos, defenderlos pretendiendo que los demás asuman ese coto como inaccesible e intocable para ellos, surgiendo entonces esa connotación de daño de lo agresivo.

3 - "Ser agresivo, de acuerdo con el sentido original, es pues avanzar hacia un objetivo, sin vacilación indebida, duda ni temor. Es sinónimo de agresivo"acometedor" (y por ende de agresividad, "acometividad") Acometedor es a su vez sinónimo de emprendedor, dinámico, decidido, impetuoso, arremetedor, arrojado.

A

4 - En inglés la palabra "aggression" no tiene el significado peyorativo que tiene en castellano, sino que se acepta con el signiicado de actividad e iniciativa. En la lengua inglesa agresividad (aggressiveness) ha terminado por perder cualquier connotación de hostilidad, convirtiéndose en sinónimo de «<espíritu de iniciativa»», <<energía, actividad》〉

Figura 5. Tratamientos etimológicos de la agresión. Elaboración propia. quien lo define en el sentido literal de su radical - $a g$ gredi, de ad gradi (gradus es "paso" y ad, "hacia"), que significa "avanzar (ir, dar un paso) hacia delante", del mismo modo que regredi significa "retroceder". Un individuo puede aggress, o sea avanzar, pero no puede aggress a alguien, en el sentido en que se puede atacar a alguien. La palabra agredir debió adquirir pronto el sentido de atacar, puesto que en la guerra el avance solía ser el comienzo de un ataque. Ser agresivo, de acuerdo con el sentido original, es pues avanzar hacia un objetivo, sin vacilación indebida, duda ni temor. Es sinónimo de agresivo acometedo (y por ende de agresividad "acometividad"). Acometedor es a su vez sinónimo de emprendedor, dinámico, decidido, impetuoso, arremetedor, arrojado, entre otros, por lo que tal vez tradujera mejor el sentido general del inglés aggressive.

Para el caso de agresividad en inglés, Giuseppe Di Sienna (1969) comenta que aggressiveness no tiene ya connotación de hostilidad ya que su uso actual se enmarca en tratarlo como iniciativa, energía o actividad.

\section{Revisando a los investigadores del asunto desde la ciencia social}

Luego de presentar los acercamientos contradictorios de la definición idiomática y de la lengua en los diccionarios, seguido de la historicidad comprensiva de lo etimológico en cuanto a los conceptos de agresión y violencia se incursiona, en este punto, en un acercamiento del cómo los definen y los tratan algunos investigadores, los cuales desde las ciencias sociales han propuesto enfoques y modelos explicativos para su comprensión y tratamiento.

Desde la sociología, el investigador Johan Galtung $^{6}$ aborda el fenómeno de las confrontaciones y conflictos humanos solo desde el ángulo de la violencia y sin manejo en su léxico de la agresión. Posteriormente se muestra a grandes trazos (cuadros) el ejercicio de expertos en el tema del comportamiento psicológico, quienes al contrario del sociólogo mencionado, no tratan de violencia sino de agresión

6 Johan Galtung, matemático y sociólogo de origen noruego, es considerado pionero de la investigación para la paz y ha presentado un enfoque sobre la comprensión y diferenciación de las formas de la violencia, desde el ejercicio institucional y una óptica sociológica. Con esta iniciativa obtuvo reconocimiento y se ha erigido como referente obligado de quienes transitan por los caminos de la construcción de mejores modos de vida y relación interhumana. 
extrema, y sus propuestas giran alrededor de la explicación de la agresión con diferentes enfoques, propósitos y poblaciones de referencia.

\section{Algunos tratamientos de violencia en investigadores de la ciencia social}

\section{Desde las preocupaciones por la paz}

El sociólogo Johan Galtung - quien afirma que el conflicto es la fuerza motriz del proceso de desarrollo humano-, dice entender la violencia como "afrentas evitables a las necesidades humanas básicas, y más globalmente contra la vida, que rebajan el nivel real de la satisfacción de las necesidades por debajo de lo que es potencialmente posible. Las amenazas de violencia son también violencia" (Galtung, 2003, p. 262) ${ }^{7}$.

Para este autor, la violencia, entendida como agresiones a la vida, es privación de necesidades que suscitan reacciones diversas de las personas, "entre las que podría darse un sentimiento de desesperanza, un síndrome de privación/frustración que se manifiesta en el interior como una auto agresión y hacia afuera como apatía y retirada" (2003, p. 266). Así mismo, afirma que "el potencial para la violencia, como para el amor, está en la naturaleza humana, pero las circunstancias condicionan la realización de ese potencial" (p. 15), incitando a ejercicios reflexivos alrededor de nuevas formas de leer, interpretar y explicar el acontecer de las sociedades humanas y el ejercicio en las relaciones sociales entre las instituciones, las personas y los grupos. Propone clasificarla en un modelo triangular interdependiente de acuerdo con los contextos, atributos y caracterizaciones del lugar y el momento en el que se desarrolla (véae figura 6). Estas son: a) violencia directa (física, verbal y psicológica); b) violencia estructural; y c) violencia cultural. Y las define de la siguiente manera:

- Entiende que la violencia directa es un acontecimiento. La refiere a la agresión física directa y a la guerra, a la violencia manifiesta física y verbal. En fin, la violencia directa es toda aquella acción que daña al cuerpo, mente o espíritu produciendo siempre efectos visibles e invisibles sobre el conjunto de lo organizacional humano.

Este autor define las necesidades básicas primarias como necesidad de supervivencia, necesidad de bienestar, identidad-necesidad de representación y necesidad de libertad.
- Por violencia estructural señala las desigualdades al interior de los Estados-nación y en las relaciones internacionales. Refiere con su concepto la presencia constante de las confrontaciones en las organizaciones sociales, o en sus propias palabras: "la suma total de todos los choques incrustados en las estructuras sociales locales y mundiales, y cementados y solidificados de tal forma que los resultados injustos, desiguales, son casi inmutables" (Galtung, 1998, p. 16). En su percepción sociológica, trata de fijar y reconocer las estructuras represivas y de explotación contenidas en la estructuración deficiente del sistema económico, ideológico y organizacional que conllevan incapacidad para satisfacer las necesidades básicas de las personas y de los grupos o colectivos: "una sociedad violenta no solo deja huellas en el cuerpo humano sino también en la mente y en el espíritu" (2003, p. 11). Y es en este contexto explicativo en el cual llama a oponer a la represión la libertad, a la explotación la equidad, sustentando el diálogo y la integración de esfuerzos participativos conscientes en la estructuración de pequeñas formas organizativas que funcionen como instrumentos opuestos a la marginación, a la fragmentación y a la segregación.

- Respecto a su tercera categoría de violencia cultural, refiere:

Por violencia cultural queremos decir aquellos aspectos de la cultura, el ámbito simbólico de nuestra existencia (materializado en religión e ideología, lengua y arte, ciencias empíricas y ciencias formales -lógica, matemáticas-) que puede utilizarse para justificar o legitimar violencia directa o estructural. Estrellas, cruces y medias lunas; banderas, himnos y desfiles militares; el omnipresente retrato del líder; discursos y carteles incendiarios (...) Se nos vienen a la mente todas estas cosas" (Galtung, 2003, p. 261).

Y en otro texto expresa como "sería la suma total de todos los mitos, de gloria y trauma y demás, que sirven para justificar la violencia directa" (Galtung, 1998, p. 16).

En resumen y de acuerdo con el profesor Jiménez (citado en López, 2004):

Bajo el concepto de violencia cultural se intentan comprender todas las facetas culturales que de una $\mathrm{u}$ otra forma apoyan o justifican las realidades y prácticas de la violencia. Si la violencia directa es generada 
desde el propio agresor y la violencia estructural está organizada desde el sistema - la estructura-, la violencia cultural lo hace desde las ideas, las normas, como alegato o aceptación "natural" de las situaciones provocadas por ella. Es decir, todo aquello que, en definitiva, desde la cultura legitime y/o promueva la violencia de cualquier origen o signo (p. 1161).

O bien como dice Galtung que la función de la violencia cultural, en cuanto a las otras, es hacer que las otras dos violencias aparezcan "e incluso se perciban, como cargadas de razón - o por lo menos no malas" (1998, pp. 261-262). De esta manera destaca lo moral, la calificación de bueno o malo, como instrumento de uso enraizado que lleva a que el ser humano divida,

Esquemáticamente los mecanismos de control en internos y externos, positivos y negativos: identificando los internos, tanto positivos como negativos como buena y mala conciencia respectivamente, los externos positivos como recompensa y los externos negativos como castigo. La interiorización es la conciencia profundamente arraigada en el sistema de la persona, la institucionalización es el concepto premio/castigo profundamente arraigado en el sistema social. Ambos sirven para que el acto surja naturalmente, con normalidad, voluntariamente (1998, p. 276).
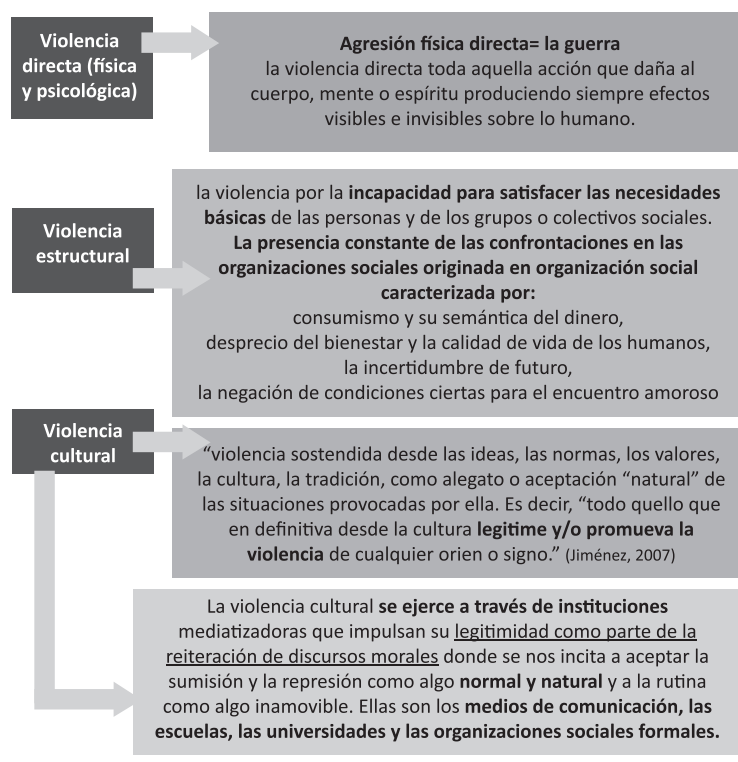

Figura 6. Los tipos de violencia de Johan Galtung (1998). Elaboración propia.
En su abordaje identificador de sus categorías fija que la violencia cultural actúa a través de instituciones mediatizadoras, las cuales actúan como transmisores de esas simbologías, impulsando su legitimidad (medios de comunicación, escuelas, universidades, organizaciones sociales formales, etc.), como parte de la reiteración de discursos en los que "la cultura sermonea, enseña, amonesta, incita y nos embota para que aceptemos la explotación y/o la represión como algo normal y natural para que no las veamos en absoluto (en especial la explotación)” (p. 265).

\section{El tratamiento de violencia desde algunos de los teóricos de la investigación de la motivación y el comportamiento humano}

Ninguno de los autores revisados habla de violencia y se refieren a agresión extrema como se ve a continuación en el cuadro-resumen de la figura 7.

\section{Algunos tratamientos de agresión en investiga- dores de la ciencia social}

A continuación se incorpora a la reflexión la selección de algunos criterios expresados en las figuras 8, 9, 10 y 11, las cuales muestran las diferentes afirmaciones

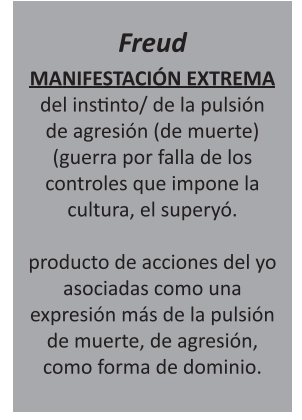

Dollard \& Miller señalan la posibilidad $D E$ AGRESIONES EXTREMAS como reacción a la frustración cuando la intensidad del deseo, de satisfacción es alta pero sin identificarla como violencia

\section{NO hablan de VIOLENCIA}

\section{Lorenz}

referencia es a la muerte en los casos de agresiones intra e inter específicas, al considerar que los patrones que desata el instinto estimulado son parte de un ritual adaptativo de la especie. No hace referencia a violencia.

Se da como propósito de supervivencia Refiere el COMPORTAMIENTO AGRESIVO EXTREMO en los humanos como producto de una conducta inadaptativa debido a la falta de inhibidores que impidan la muerte de los perdedores

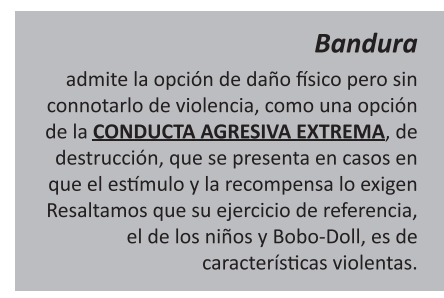

Figura 7. Tratamiento de violencia de cuatro autores clásicos (no hablan de violencia, hablan de agresión). Elaboración propia. 
El instinto de agresión expresa su inevitable disposición a actuar Actuación a partir de la cual se dan los vínculos amorosos entre las personas así como el goce sádico, la rabia destructora y la violencia como formas de tendencia a dominar.

Presente en todos
los sentimientos de
la persona como
parte constitucional
humana y no como
reacción a estímulos
sino como cualidad
emergente,
inevitable en la
sintomatología y en
la vida humana

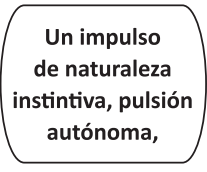

la agresión se originaría cuando herida narcisista, más por el obstáculo, la privación o el rechazo que por la no satisfacción de las pulsiones. el yo sufre esta
En la dinámica de la relación con los objetos no toda insatisfacción conduce a una agresión. Cuando el YO se siente herido o amenazado busca la eliminación o destrucción de todos los objetos perturbadores que son fuente de frustración de la satisfacción sexual o de la satisfacción de necesidades de conservación.
Figura 8. Definición y tratamientos de agresión en Sigmund Freud (1915a, 1915b, 1930, 1932). Elaboración propia.

de los cuatro autores clásicos que se han tomado como referencia para dilucidar las conceptualizaciones que se dan sobre la agresión. Se pretende con ello que se observen los diversos matices, variantes e implicaciones que conlleva el reconocimiento del ejercicio de las acciones llamadas agresivas, y se evite así el tratamiento simplista que ha generado y continua generando confusión en el abordaje de los asuntos que motivan a comprender la agresión y la violencia.
Un instinto al servicio de la conservación, supervivencia individual y de la especie que puede o no producir daño.

(1)

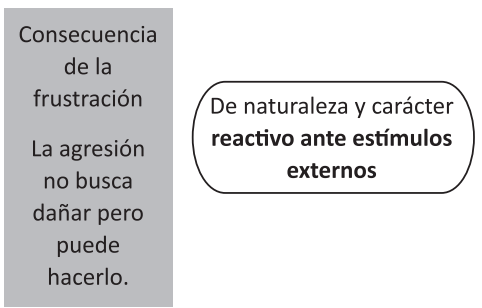

No necesariamente toda frustración ha de desencadenar en una agresión pues lo que provocaría sería un estado de incitación a la agresión expresada en consideración al contexto social reacción ante la frustración de las respuestas de búsqueda de placer o evitación del dolor presente cuando un individuo no logra alcanzar su objetivo o no obtiene la recompensa deseada.
La agresión es un impulso limitado por factores externos que la pueden inhibir u obligar a diferir su propia fuerza, acumulándose luego de ser instigada, buscando expresarse inevitablemente para reducir la energía propia que estimula la frustración.

Figura 10. Definición de Agresión según Dollard, Miller, Doob, Mowrer y Sears (1939). Elaboración propia.

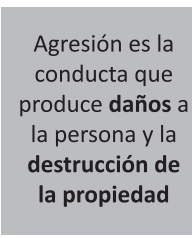

La lesión puede adoptar formas psicológicas de devaluación y de degradación lo mismo que de daño físico.

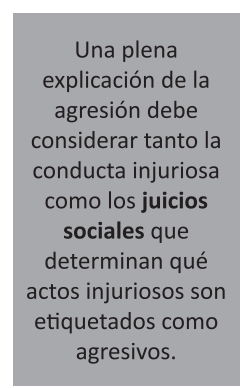

las personas no nacen con repertorios prefabricados de conducta agresiva ya que estas son aprendidas, es decir, estas se aprenden observando, deliberada o inadvertida, acciones de otros de donde emerge la idea y, de allí, se pueden aprender estrategias generales que dan la guía para trascender los ejemplos concretos modelados condicionada su calificación a intervenciones sociales que determinan el juzgamiento de los actos perjudiciales y les clasifican como de índole agresiva o no según juicios personales surgidos de si la conducta fue intencional o no y donde intervienen otros factores y los valores propios de los clasificadores afectan la manera en que las actividades son interpretadas.
Figura 11. Definición de agresión según Albert Bandura (1973, Es la espontaneidad del instinto la que lo hace tan temible.

Figura 9. Definición de agresión según Konrad Lorenz (1963, 1965). Elaboración propia. motivación en de los grupos por esencia de un enemigo. a fuerzas
1976). Elaboración propia.

En las afirmaciones, tratamientos y explicacio-

nes anteriores se observan diferencias en el tratamiento con relación a la concepción de su naturaleza y a sus efectos, los cuales emanan a consecuencia de la variedad de factores que intervienen en el ejercicio 
particular de cada uno de ellos, tales como son sus diferentes contextos, poblaciones y situaciones, en relación con el universo en el que se realizaron sus investigaciones, así como diferencias en su metodología, intereses, objetivos y nivel de exigencia operativa. Esto requiere una mirada comparativa, la cual permita hallar los elementos que faciliten o no ver su complementariedad y alternancia, y no con el esquema de contraposición irreconciliable de las discusiones filosóficas e ideológicas.

En el esquema sobre cada autor se reitera que el fenómeno de su competencia gira alrededor de la agresión y no de la violencia, así como se ve que su ejercicio explicativo se centra en la comprensión de la dinámica, de modo que implica lo individual o lo subjetivo en su relación social y no en los asuntos de la violencia física, y la causalidad que atrae a los medios periodísticos.

\section{Consideraciones y propuestas}

\section{Algunas consideraciones, propuestas y esquemas para el debate}

A continuación, se examinan - a manera de conclusión-, algunas consideraciones, propuestas y esquemas producto de la discusión de los resultados asistidos por algunas propuestas y esquemas, los cuales pretenden invitar al debate académico con el propósito de lograr mayor comprensión del fenómeno de la violencia escolar, así como de todo tipo de contacto interhumano en el que los conceptos de agresión y violencia sean susceptibles de ser evocados.

Las siguientes reflexiones se sitúan, de alguna manera, como puntos de naturaleza axiomática surgidos en las intensas reflexiones suscitadas sobre la investigación documental - lo cual ha permitido fundamentar esta ponencia-, y son discusiones que, por la brevedad exigida para el texto, resulta imposible relatar en toda su extensión.

1. Al revisar el tratamiento en los diccionarios descrito en párrafos anteriores, se resalta la confusión que genera la ambigüedad y la sinonimia en la diferenciación de los términos agresión y violencia, y sus variantes, lo cual conduce a renunciar a sus definiciones como referente para los análisis del tema en tratamiento.

2. Un especial aporte resulta lo expuesto por los expertos en etimología, de manera que es posible dilucidar el sentido de los dos términos e intentar comprender su diferencia y ligazón. De allí que se considera en esta indagación válido comprender el término agresión ligado al concepto de movimiento, e identificar su sentido en la acción relacional entre seres vivos, entendiéndolo como "ir hacia", "dirigirse", "acercarse", "aproximarse al otro", a alguien. Así como en el sentido de acometer, que indica movimiento con energía propia. Así mismo, se considera que el término violencia ha de ser tratado también como concepto relacional entre seres vivos o elementos que se han movido, que se mueven y chocan con fuerza, con abuso de esta y en el cual está presente el uso de la fuerza física. Y, al enfatizar su activación racional, su instrumentalidad, se llama la atención sobre el hecho de que la violencia como daño se da únicamente en los humanos. De acuerdo con Jiménez-Bautista (2012): "el ser humano es conflictivo por naturaleza, pero pacífico o violento por cultura” (p. 14).

3. Cotejando las diferencias explicativas de los diversos autores revisados, se destaca, en aras de la claridad conceptual y la exigencia comprensiva, que el autor no reconoce calificación de polisémicos a los términos de agresión y violencia, en cuanto ello autorizaría el uso superficial de sus significados y significaciones como ha venido sucediendo por la falta de profundización conceptual, teórica y metodológica de muchos de quienes fungen de eruditos circunstanciales en el tema. Se propone que se deben entender las diferencias explicativas dadas por los autores a partir de contextualizar tanto sus concepciones epistemológicas, como las condiciones y exigencias de su praxis particular, su vocación, su exigencia operativa, su nivel de exigencia pragmática e intervención, sus propósitos institucionales y profesionales, así como su acción investigativa enmarcada en diseños metodológicos emanados de su definición de sus objetos de estudio ligados a poblaciones, intereses y muestras específicas.

4. También es pertinente considerar que la racionalidad no es omnipresente en todos los encadenamientos en los que pueden reconocerse efectos violentos, pues estos podrían no causarse como resultado de una acción preconcebida o deliberada, sino darse como parte de un proceso en el cual en su génesis se gestiona con una lógica singular a partir de complejos sentimientos y emociones, disparados automáticamente bajo los códigos culturales. En estos, por ejemplo, la irritación, la 


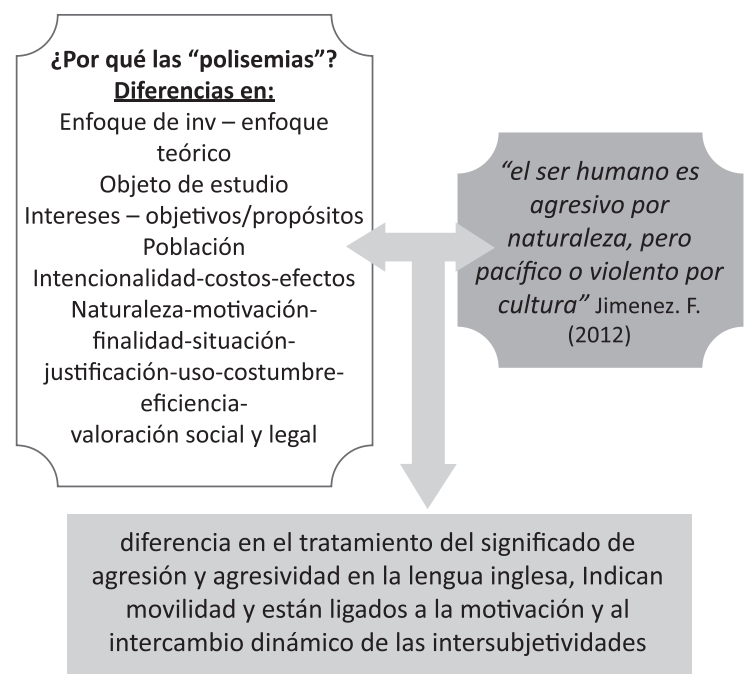

Figura 12. Tres propuestas iniciales. Elaboración propia.

molestia, el agravio y todo tipo de afectación subjetiva de las partes logra desencadenar una escalada progresiva, en espiral, de aumentos de frecuencia y de intensidad en la fuerza aplicada, de manera que conlleva a la generación de actos y hechos que producen daño, destrucción y afectación irreversible.

5. Se convoca a revisar las cotidianas contradicciones en el uso ambiguo y ambivalente del concepto de violencia, situación que ejemplariza sobre algunos deportes como el boxeo, la lucha, el rugby y algunos juegos de video, en los cuales se apoyan en el estímulo de ejercicios que implica dañar o inhabilitar al definido como enemigo o adversario, a quien proponen vencer inteligente pero inmisericordemente. Ejemplo de cómo mientras se descalifica la violencia desde ángulos morales, éticos y educativos, se estimula en la praxis competitiva como factor de mérito si es exitoso.

6. Se invita a entender la agresión y la violencia no como sinónimos sino como parte de un mismo fenómeno de naturaleza social, un continuo como se representa en figura 13, en el cual la manifestación o presencia de cualquiera de ellas se define en términos de la potencia de las fuerzas implicadas, de la capacidad para definir, moderar o intervenir la intensidad, la persistencia y la frecuencia de la fuerza emitida o receptada desde las subjetividades implicadas, en función de la lógica particular desencadenada, y la cual impregna los momentos y les da el matiz de urgencia o su opción de espera.
Tal como se hace implícito en los cuatro investigadores del comportamiento en los que la violencia sería entendida como agresión extrema.

7. El autor entiende que el fenómeno del contacto interpersonal o interinstitucional está regido por un juego de tensiones y afectaciones que definen su movilidad y tendencia. Dentro de este juego relacional en el que emergen contrastes y la percepción diferencial de emociones y sentimientos, se permiten tomar forma y contenido en la medida de la fuerza del impacto del uno sobre el otro, demandando que la subjetividad se posicione como tablado, escenario y al mismo tiempo como actriz que connota y da significado al contacto. Estas significaciones móviles parecieran regidas por las afectaciones personales emergentes que facilitan alertas o distensiones según las particularidades de este juego de ires y venires, en el que fluctúa el encuentro interhumano. Por ello, es en esta compleja trama de emociones y sentimientos en la que se da la percepción de haber sido agredido, en la medida en que se desordena la rutina y aparece lo inesperado, lo inusual, lo potencialmente absurdo que dispara las alertas $y$, en su tensión, convoca al arsenal cultural del que se dispone para responder a las amenazas. Y si el impacto es más fuerte y/o sostenido en su frecuencia y reiteración, se llega a niveles extremos de la estimulación que evocan lo agresivo para, en vez de relajar las alertas, llevar a cruzar la invisible línea entre esta y la violencia, de manera que se ingresa al universo de lo violento del acto que elimina la posibilidad constructiva del contraste, y así configurar un escenario de destructividad y de imposición que vulnera las lógicas productivas e igualitarias pregonadas socialmente.

Se propone la pertinencia de mirar el acercamiento a la fenomenología del continuo de los dos polos de lo agresivo y lo violento como pertinente, y entenderlos como parte del mismo fenómeno emergente de la naturaleza dinámica y crítica del contacto interhumano. Conveniente sería el tratar de entender en qué momento la percepción agresiva muta, se convierte en violencia. En esta reflexión se cree que esto solo es descifrable en la particularidad de la relación interpersonal o interinstitucional ejecutada en el tramado de los condicionantes y las relaciones de poder. Es necesario tener en cuenta en los acercamientos al fenómeno que la violencia debe mirarse como la manifestación extrema de agresión, en la cual su flujo se da en las dos direcciones, al ser los dos polos de un continuo. 
Son parte del mismo proceso del contacto interhumano se diferencian en su frecuencia, en su intensidad, en sus efectos y la recursividad desencadenada.

\section{LA VIOLENCIA DEBE MIRARSE COMO LA MANISFESTACIÓN EXTREMA DE AGRESIÓN}

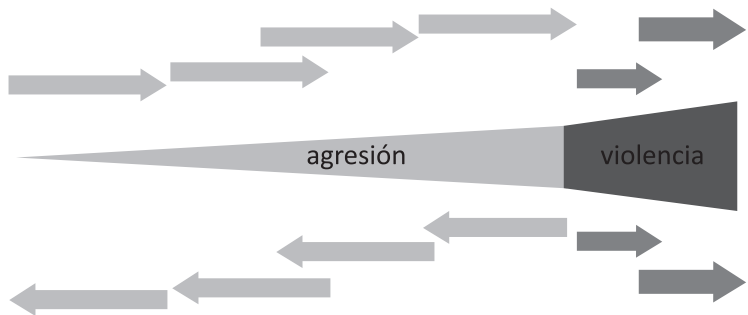

persistencia, repetición e intensidad

Figura 13. Propuesta de línea continua de la agresión y la violencia. Elaboración propia.

8. El acto agresivo o la agresión es el producto del movimiento inherente a los seres vivos cuando se desarrolla en espacios limitados. Entre más cerrado es el límite y más rígido, aumenta las probabilidades de que suceda el choque entre quienes se encuentran en su interior. La tendencia del choque es a resolverse en forma automática, pero solo hasta que el impacto altera algún componente de la estructura de una de las partes (merced a la fuerza implicada y a la frecuencia del choque), y desata la probabilidad de traspasar la invisible línea que divide lo agresivo de lo violento. Dado lo anterior, se propone la siguiente afirmación axiológica a tener presente: Toda acción o movimiento en espacios limitados es susceptible de ser percibida como agresiva, y hace considerar que es imposible evitar la agresión; ella es parte de la naturaleza de lo vital. Lo violento es exclusivamente humano y de naturaleza socio-cultural.

Toda acción o movimiento en espacios limitados... es susceptible de ser percibida como agresiva

9. A continuación se presenta un cuadro-resumen en la figura 14, el cual representa el continuo y la caracterización de agresión y violencia a partir de los elementos comunes de tensión-crisis, y la condición de desatar la alerta/amenaza. Se destaca la constructividad potencial de la agresión y la condición de destructividad que identifica la violencia. Así mismo, en el cuadro se encuentra implícita la idea que plantea como para que un conflicto se desate entre personas naturales o jurídicas, es indispensable que alguna de las partes se perciba como agredida en montos que la obligan a desatar sus alertas, su percepción de amenaza y disponer sus recursos para la defensa y/o el ataque. A partir de ese momento de crisis se determinan tanto las características del conflicto, como sus posibilidades de solución pronta, o el desencadenamiento de espirales de agresión in crescendo que van mutando en violencia.

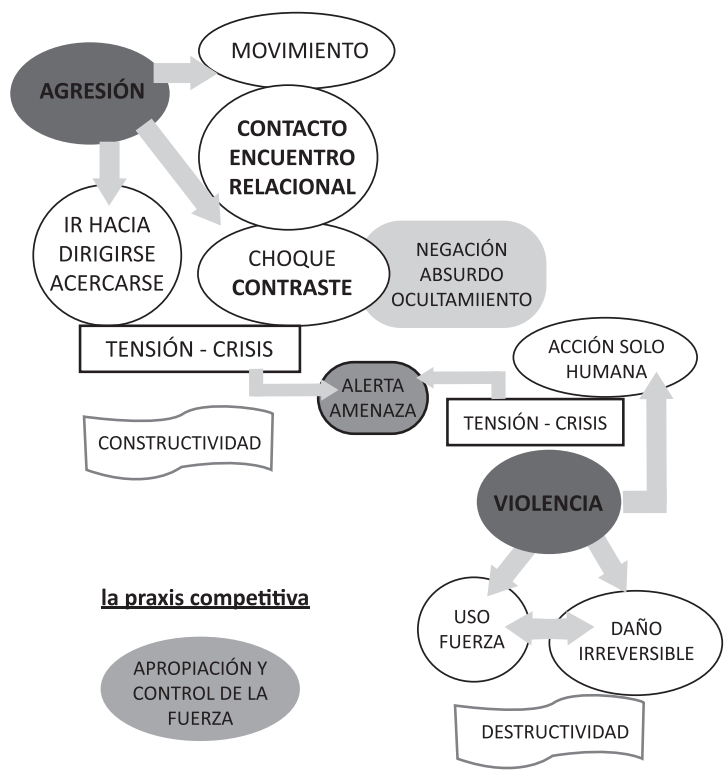

Figura 14. Propuesta de punto de intersección de la agresión y la violencia. Elaboración propia.

En este orden reflexivo es una opción plantear la hipótesis según la cual lo que posibilita el paso de agresión a violencia por parte de quien se posiciona como victimario, es la limitación en la capacidad de respuesta y la fragilidad de quien es considerada la víctima (quien opta por recursos como la pasividad, el silencio, el autocontrol y la simulación como salidas usuales a la rigidez de la fuerza del contacto, a la ineludibilidad aparente del orden que sustenta la praxis competitiva y a todos aquellos mecanismos 
institucionales que convocan al imperio del control, la seguridad y el autoritarismo de universos cerrados y anquilosados en sus prácticas de poder).

Para finalizar el ejercicio reflexivo se propone utilizar el concepto de violencia cuando los sucesos que se refieran impliquen que alguien hace daño a otro, y se entienda la agresión como fenómeno omnipresente en todo movimiento de los seres vivos en cuanto conlleva la opción posible y probable de ser desencadenante de crisis y oportunidades. Cabe retomar, además, la idea subyacente en los cuatro investigadores clásicos, en la que se entiende la violencia como una agresión extrema.

\section{Referencias}

Arnal, M. (2009a). Etimología de Agresión. Revista digital El Almanaque, 1279. Recuperado de http://www.elalmanaque.com/lexico/agresion.htm.

Arnal, M. (2009b). Agresión en medicina. Revista digital El Almanaque, 21-26. Recuperado de http://www.elalmanaque.com/Medicina/lexico/agresivo.htm

Bandura, A. (1973). Aggression. A social learning analysis. New Jersey: Prentice Hall.

Bandura, A. (1976). Teoría del aprendizaje social. Madrid: Espasa Calpe.

Di Sienna, G. (1969). Ideologías del biologismo. Barcelona: Anagrama.

Dollard, J., Miller, N., Doob, L., Mowrer, H. y Sears, R. (1939). Frustration and aggression. New Haven: Yale University Press.

Elcastellano.com. (s. f.). Sobre la violencia. Recuperado de http://www.elcastellano.org/palabra/violencia

Elcastellano.com. (s. f.). Etimología. Recuperado de http:// www.elcastellano.org/palabra.php/?-id=1259

Freud, S. (1915a). Las pulsiones y sus destinos. En Obras Completas (Vol. vi). Madrid: Biblioteca Nueva.

Freud, S. (1915b). Consideraciones actuales sobre la guerra y la muerte. Madrid: Biblioteca Nueva.
Freud, S. (1930). El malestar en la cultura. Madrid: Alianza Editorial.

Freud, S. (1932). ¿Por qué la Guerra? Madrid: Biblioteca Nueva.

Fromm, E. (1982). Anatomía de la destructividad humana. Madrid: Siglo XxI Editores.

Galtung, J. (1998). Tras la violencia, 3R: reconstrucción, reconciliación, resolución. Afrontando los efectos visibles e invisibles de la guerra y la violencia. Bilbao-Gernika: Bakeaz /Gernika Gogoratuz.

Galtung, J. (2003). Paz por medios pacíficos: paz y conflicto, desarrollo y civilización. Bilbao: Bakeaz/Gernika Gogoratuz.

Jiménez, F. (2007). Sobre la violencia y sus causas. En F. Jiménez y M. López (Eds.), Hablemos de paz (pp. 99124). Pamplona: Universidad de Pamplona.

Jiménez-Bautista, F. (2012). Conocer para comprender la violencia: origen, causas y realidad. Convergencia. Revista de Ciencias Sociales, 19(58) 13-52. Recuperado de http://www.redalyc.org/articulo.oa?id=10520680001

López, M. (2004). Enciclopedia de paz y conflictos (Eirene). Granada: Ed. Universidad de Granada Recuperado de http://www.ugr.es/ raipad/proyectos/iberoamerica/ items/violencia_cultural.pdf

Lorenz, K. (1963). Sobre la agresión el pretendido mal. México: Siglo xxi Editores.

Lorenz, K. (1965). El comportamiento animal y humano. Barcelona: Plaza \& Janés.

Miller, N. y Dollard, J. (1941). Social learning and imitation New Haven: Yale University Press.

Moliner, M. (1983). Diccionario de uso del español. Madrid: Gredos.

RAE. (1992). Diccionario de la lengua española. Madrid: XXI Edición Espasa Calpe.

Van Rillaer, J. (1978). La agresividad humana. Barcelona: Herder. 